\title{
Antisense oligonucleotides as a potential treatment for brain deficits observed in myotonic dystrophy type 1
}

\author{
Siham Ait Benichou ${ }^{1}$, Dominic Jauvin ${ }^{1,2}$, Thiéry De Serres-Bérard ${ }^{1,2}$, Marion Pierre ${ }^{2}$, Karen K. Ling $\mathbb{D D}^{3}$, C. Frank Bennett ${ }^{3}$, Frank Rigo ${ }^{3}$,
} Genevieve Gourdon ${ }^{4}$, Mohamed Chahine (iD ${ }^{2,5}$ and Jack Puymirat ${ }^{1,5}$

(c) The Author(s) 2022

\begin{abstract}
Myotonic dystrophy, or dystrophia myotonica type 1 (DM1), is a multi-systemic disorder and is the most common adult form of muscular dystrophy. It affects not only muscles but also many organs, including the brain. Cerebral impairments include cognitive deficits, daytime sleepiness, and loss of visuospatial and memory functions. The expression of mutated transcripts with CUG repeats results in a gain of toxic mRNA function. The antisense oligonucleotide (ASO) strategy to treat DM1 brain deficits is limited by the fact that ASOs do not cross the blood-brain barrier after systemic administration, indicating that other methods of delivery should be considered. ASO technology has emerged as a powerful tool for developing potential new therapies for a wide variety of human diseases, and its potential has been proven in a recent clinical trial. Targeting DMPK mRNA in neural cells derived from human induced pluripotent stem cells obtained from a DM1 patient with the IONIS 486178 ASO abolished CUG-expanded foci, enabled nuclear redistribution of MBNL1/2, and corrected aberrant splicing. Intracerebroventricular injection of the IONIS 486178 ASO in DMSXL mice decreased the levels of mutant DMPK mRNAs by up to $70 \%$ throughout different brain regions. It also reversed behavioral abnormalities following neonatal administration. The present study indicated that the IONIS 486178 ASO targets mutant DMPK mRNAs in the brain and strongly supports the feasibility of a therapy for DM1 patients based on the intrathecal injection of an ASO.
\end{abstract}

Gene Therapy (2022) 29:698-709; https://doi.org/10.1038/s41434-022-00316-7

\section{INTRODUCTION}

Myotonic dystrophy or dystrophia myotonica type 1 (DM1), also known as Steinert disease, was first described in 1909 by Steinert. It is a neuromuscular disorder that affects several organs and is the most common adult form of muscular dystrophy [1, 2]. DM1 is an autosomal dominant disease associated not only with progressive muscle weakness and myotonia but also with broad clinical features, including cardiac involvement, endocrine deficiencies, and central nervous system (CNS) alterations [1, 3, 4]. A peculiarity of this disease is a severe congenital form associated with $20 \%$ neonatal mortality $[5,6]$, mental and intellectual disabilities, psychomotor disorders, and motor retardation in surviving infants [7-9]. Cerebral impairments observed in adult DM1 include anxiety, loss of visuospatial functions and memory, apathy, and daytime sleepiness. Overall, the quality of life of DM1 patients is drastically impacted by their cognitive deficits $[10,11]$. Neurological afflictions are also associated with histopathological changes such as heterotopic neurons in the case of congenital DM1 [12, 13] and the aggregation of hyperphosphorylated fetal human TAU isoforms in adults, particularly in the hippocampus, amygdala, and entorhinal and temporal cortices $[14,15]$. Young patients with congenital DM1 manifest severe brain structure abnormalities such as ventricular dilatation, cortical atrophy, and white matter lesions [12,13,16-18]. Neurodevelopmental defects are specific to early-onset DM1, while the CNS features of the adult form are reminiscent of neurodegenerative diseases [19].

DM1 is caused by an unstable expansion of CTG repeats in the $3^{\prime}$ UTR region of the dystrophia myotonica protein kinase (DMPK) gene located on chromosome 19q13.3 [20-23]. Unaffected individuals have 5-37 CTG repeats. When the repeat number exceeds 50 CTGs, this usually leads to disease manifestation, while larger repeat sizes are associated with an increase in the severity of symptoms. RNA transcripts containing CUG-expanded repeats (CUGexp-RNA) accumulate in nuclear aggregates (foci) that interfere with two families of RNA-binding proteins: CUGBP-Elavlike (CELF) and muscleblind-like (MBNL) proteins [24-28]. MBNL loss of function through sequestration in intranuclear RNA foci and CELF1 upregulation primarily perturb developmentally regulated splicing events. This not only results in the aberrant production of fetal isoforms in affected adult tissues [21, 29] but also affects RNA transcription, polyadenylation, and localization; protein translation; and miRNA processing [30-35]. The extent of these events in the CNS, how they contribute to neuropathogenesis, and their cellular specificity are not known [36].

Mouse [37-44], Drosophila [45-47], zebrafish [48, 49], and patient-derived induced pluripotent stem cell (iPSC) models are used to study the biological mechanisms underlying the DM1 pathology and to test possible therapeutic strategies [50]. Recent

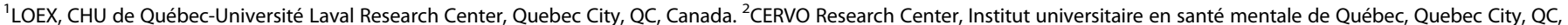

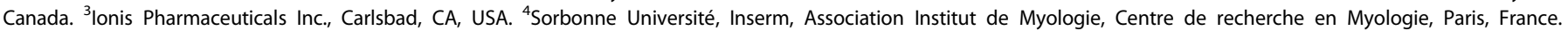
${ }^{5}$ Department of Medicine, Faculty of Medicine, Université Laval, Quebec City, QC, Canada. ${ }^{凶}$ email: mohamed.chahine@phc.ulaval.ca 
studies have confirmed DM1 phenotypes in iPSCs [50-53] and have made it possible to study the pathology using several DM1 cell types, some of which are less accessible than others. Several transgenic mice models have also been generated to investigate the pathophysiology of DM1. The DMSXL mouse model was designed to express a mutant form of the human DMPK gene with more than 1000 CTG repeats [37, 38]. Homozygote DMSXL mice express toxic transcripts that disrupt muscle, heart, brain, and respiratory functions by forming RNA foci and generating missplicing events $[32,54-56]$. The expression of mutated DMPK mRNAs in the CNS reduces short-term synaptic potentiation in DMSXL mice and affects behavior functions, resulting in low levels of exploratory activity, spatial memory impairment, increased anxiety, and anhedonia [32].

No curative treatment is available for DM1 patients. Advances in the understanding of DM1 pathophysiological mechanisms indicate that inhibiting intranuclear RNA foci is a valuable therapeutic strategy. It has been shown in preclinical studies that antisense oligonucleotides (ASOs) with gapmer designs induce the degradation of intranuclear RNA foci both in vitro and in vivo through the RNase-H mechanism [57-60]. ASOs are also being investigated as therapeutic agents for multiple diseases, including diabetes, hyperlipidemias, cardiovascular diseases, cancer, and neurodegenerative diseases. Some ASO chemistries such as MOE and cEt have been proven to be effective for heart and skeletal muscle delivery and for correcting muscle phenotypes and cardiac conduction defects after systemic administration in DM1 mouse models expressing expanded CUG-mRNAs [58, 59, 61]. These results led to the first DM1 clinical trial based on ASO strategies (clinical trial NCT02312011). A major limitation of ASOs is that they do not efficiently cross the blood-brain barrier following systemic administration [59], indicating that other delivery methods are necessary to correct CNS deficits in DM1. A proof of concept study based on the intrathecal delivery of ASOs has shown that ASOs are effective in treating spinal muscular atrophy (SMA) [62].

We evaluated the effectiveness of the IONIS 486178 ASO in correcting the DM1 phenotype in human neuronal cells derived from iPSCs as well as cognitive impairments in DMSXL mice. We also characterized the pharmacodynamics and toxicity of the IONIS 486178 ASO in the CNS.

\section{MATERIALS AND METHODS \\ Derivation of iPS cell lines}

Human fibroblast cells from a control individual as well as from a patient with infantile-onset DM1 and a severe intellectual disability were reprogrammed using the Cytotune ${ }^{\mathrm{TM}}$-iPS 2.0 Sendai virus reprogramming kit according to the manufacturer's instructions (Thermo Fisher Scientific, Ottawa, ON, Canada). Briefly, $2 \times 10^{5}$ fibroblasts were transduced in six-well plates with an MOI of 5 for the KOS and hc-Myc viruses and an MOI of 3 for the hKIf4 virus. Seven days after transduction, the fibroblasts were transferred onto irradiated mouse embryonic fibroblast cells (MEFs) in hES medium (DMEM/F12) containing 20\% knockout serum replacement, $1 \%$ GlutaMax $^{\mathrm{TM}}, 1 \%$ non-essential amino acids, and $0.1 \mathrm{mM}$ 2-mercaptoethanol (all from Gibco, Grand Island, NY, USA) supplemented with $10 \mathrm{ng} / \mathrm{mL}$ of FGF2 (StemCell Technologies, Vancouver, BC, Canada). Colonies with an iPSC-like morphology were manually picked after $\sim 20$ days. iPSCs were expanded on Matrigel-coated plates (Becton Dickinson, Mississauga, ON, Canada) with $\mathrm{mTeSR}^{\mathrm{TM}}$ (StemCell Technologies), passaged with $0.5 \mathrm{mM}$ EDTA (Thermo Fisher Scientific) in D-PBS (Millipore Sigma, Oakville, ON, Canada) every 3-4 days, and cryopreserved in Cryostem $^{\mathrm{TM}}$ Freezing Medium (StemCell Technologies). The cells were routinely checked for mycoplasma contamination using Venor GeM Mycoplasma OneStep PCR detection kits (Minerva Biolabs, Berlin, Germany), and the identity of a reprogrammed sample was verified by STR analysis (Genome Quebec, QC, Canada).

For embryoid body (EB) formation, the iPSCs were dissociated into single cells using Accutase (Stemcell Technologies) and were transferred into standing $25-\mathrm{cm}^{2}$ flasks. The cell cultures were suspended in $\mathrm{mTeSR} 1$ medium supplemented with $10 \mu \mathrm{M}$ Y-27632 (LC Laboratories, Woburn, MA,
USA). After $24 \mathrm{~h}$, the medium was changed to EB medium (DMEM/F12, 20\% knockout serum replacement, $1 \%$ non-essential amino acids, $1 \%$ Gluta$\mathrm{MAX}^{\mathrm{TM}}$, and $0.1 \mathrm{mM}$ 2-mercaptoethanol) supplemented with $10 \mu \mathrm{M}$ $\mathrm{Y}$-27632. The EBs were cultured in suspension for 8 days, plated on $0.1 \%$ gelatin-coated six-well plates, cultured for another 8 days, and then analyzed for three-germ-layer differentiation.

\section{Neural differentiation}

Neural differentiation was performed using the neural rosette method in AggreWell $^{\mathrm{TM}} 800$ microwell culture plates (Stemcell Technologies) according to the manufacturer's instructions. Briefly, $3 \times 10^{6}$ iPSC cells were added to the wells of the culture plates. The wells contained STEMdiff' ${ }^{\mathrm{T}}$ Neural Induction Medium (NIM, StemCell Technologies) supplemented with $10 \mu \mathrm{M}$ Y-27632. The cells were centrifuged at $100 \times$ $g$ for $3 \mathrm{~min}$ and were then cultured for 5 days in the same media without Y-27632. EBs were then plated on Matrigel-coated plates and were cultured for 7 days. The resulting neural rosettes were collected using STEMdiff ${ }^{\text {TM }}$ Neural Rosette Selection Reagent (StemCell Technologies) and were transferred to poly-L-ornithine- $(15 \mu \mathrm{g} / \mathrm{mL}$, Millipore Sigma) and laminin- $(10 \mu \mathrm{g} / \mathrm{mL}$, StemCell Technologies) coated six-well plates. Neural rosettes and neural progenitor cells (NPCs) were cultured for 7 days in NIM and were then treated with Accutase to produce single-cell suspensions. NPCs were cultured in STEMdiff ${ }^{\mathrm{TM}}$ Neural Progenitor Medium (StemCell Technologies) and were treated with Accutase to produce single-cell suspensions. They were differentiated by culturing them in STEMdiff ${ }^{\mathrm{Tm}}$ Neuron Differentiation Medium (StemCell Technologies) for 7 days. Poly-ornithine-laminin-coated plates were seeded at $5 \times 10^{4}$ cells/ $\mathrm{cm}^{2}$, and the cells were cultured for 15 days in STEMdiff ${ }^{\mathrm{TM}}$ Neuron Maturation Medium (StemCell Technologies).

\section{Immunofluorescence}

The cells were fixed in 4\% paraformaldehyde for $15 \mathrm{~min}$ at room temperature, rinsed with phosphate-buffered saline (Millipore Sigma), permeabilized, and blocked with $2 \%$ BSA (Millipore Sigma) supplemented with $10 \%$ goat serum (Gibco) and $0.2 \%$ Triton X-100 (Millipore Sigma) for $30 \mathrm{~min}$. They were incubated with primary antibodies for $1 \mathrm{~h}$ and then with secondary antibodies for 30 min (Alexa Fluor, Thermo Fisher Scientific). See Table S1 for a list of the antibodies used. Nuclei were stained with DAPI $(0.1 \mu \mathrm{g} / \mathrm{mL})$, and the cells were imaged using a Zeiss Axio Imager (Carl Zeiss Microscopy, Jena, Germany) microscope.

\section{Electrophysiological experiments}

Action potentials (APs) of iPSC-derived neurons were recorded from spherical single cells that exhibited bright cell bodies and two or more neurites on day 15 post-differentiation in the current-clamp mode. The membrane voltage was clamped at $-60 \mathrm{mV}$, and the APs were elicited using the following current-clamp steps: 0 pA for $200 \mathrm{~ms}$ followed by $5 \mathrm{pA}$-steps from 0 to $100 \mathrm{pA}$ over $800 \mathrm{~ms}$. The cell-attached patch-clamp in gap-free mode approach was used to record spontaneous APs. Patch electrodes were pulled from Corning 8161 borosilicate glass capillaries (Harvard Apparatus Canada, Saint-Laurent, QC, Canada) and were fire polished before the recordings. Patch electrodes were filled with an intracellular solution containing (in $\mathrm{mM}$ ): $130 \mathrm{KMeSO}_{4}, 10 \mathrm{di}-\mathrm{Na}$ phosphocreatine, 10 HEPES, $2 \mathrm{MgCl}_{2}, 2 \mathrm{Mg}$-ATP, and $0.4 \mathrm{GTP}$ and have a resistance of $6-7 \mathrm{~m} \Omega$. The $\mathrm{pH}$ was adjusted to 7.3 with $1 \mathrm{~N} \mathrm{KOH}$. The bath solution contained (in $\mathrm{mM}$ ): $154 \mathrm{NaCl}, 5.6 \mathrm{KCl}, 2 \mathrm{CaCl}_{2}, 1 \mathrm{MgCl}_{2}, 8 \mathrm{D}$ glucose, and 10 HEPES. The pH was adjusted to 7.3 with $1 \mathrm{~N} \mathrm{NaOH}$.

$\mathrm{Na}^{+}$currents were recorded as previously described [63]. Briefly, we used low-resistance, fire-polished pipets $(\approx 1 \mathrm{M} \Omega)$ filled with the following intracellular solution (in mM): $35 \mathrm{mM} \mathrm{NaCl}, 105 \mathrm{mM} \mathrm{CsF}, 10 \mathrm{mM} \mathrm{EGTA}$, and $10 \mathrm{mM}$ HEPES. The $\mathrm{pH}$ was adjusted to 7.3 with $2 \mathrm{M} \mathrm{CsOH}$ solution. The external solution contained (in $\mathrm{mM}$ ): $150 \mathrm{NaCl}, 2 \mathrm{KCl}, 1.5 \mathrm{CaCl}_{2}, 1 \mathrm{MgCl}_{2}, 10$ glucose, and 10 HEPES. The $\mathrm{pH}$ was adjusted to 7.4 with $2 \mathrm{M} \mathrm{HCl}$ solution.

APs and $\mathrm{Na}^{+}$currents were recorded with an Axopatch 200 amplifier (Molecular Devices, San Jose, CA, USA) at room temperature using 4 cells per condition. The recordings were acquired using pClamp software (Molecular Devices). Electrical signals were filtered at $5 \mathrm{kHz}$, digitized at 10 $\mathrm{kHz}$, and stored on a computer equipped with an analog-to-digital converter (Digidata 1300; Molecular Devices) for further analysis.

\section{Fluorescent in situ hybridization (FISH)}

FISH was carried out as described previously [59]. Briefly, cells were grown on Matrigel-coated coverslips and were fixed with $4 \%$ formaldehyde for 15 
$\mathrm{min}$ at room temperature. They were then permeabilized with $0.4 \%$ Triton X-100 (Millipore Sigma) and were rehydrated with a 50\% formamide (Thermo Fisher Scientific)/2X SSC buffer (Millipore Sigma) solution for 5 min. The cells were then incubated for $2 \mathrm{~h}$ at $37^{\circ} \mathrm{C}$ in hybridization buffer composed of $50 \%$ formamide, $2 X$ SSC, $1 \mathrm{mg} / \mathrm{mL}$ of yeast tRNA (Millipore Sigma), 10\% dextran sulfate (Thermo Fisher Scientific), 0.02\% BSA, $2 \mathrm{mM}$ vanadyl ribonucleoside complex (Millipore Sigma), and $1 \mathrm{ng} / \mu \mathrm{L}$ of $5^{\prime}-\mathrm{Cy} 3-$ labeled (CAG)5 PNA probe (PNA Bio, CA, USA). Following two 30-min washes in $50 \%$ formamide/2X SSC solution at $37^{\circ} \mathrm{C}$, the samples were counterstained with $0.1 \mu \mathrm{g} / \mathrm{mL}$ of DAPI (Millipore Sigma) and were mounted with Fluoromount (Millipore Sigma). Images were acquired using an LSM 700 confocal microscope with a Zeiss Axio Imager (Carl Zeiss Microscopy). FISH quantification of 500 nuclei per condition was performed using ImageJ $1.47(\mathrm{NIH})$ software.

\section{PCR}

RNA was isolated from liquid nitrogen flash-frozen mouse brains for RTqPCR. A crude extract was obtained by homogenizing and thawing tissues for $30 \mathrm{~min}$ at $55^{\circ} \mathrm{C}$ in a proteinase $\mathrm{K}$ solution containing $10 \mathrm{mM}$ Tris-Cl, pH 7.5 (Wisent Bioproducts, St-Bruno, QC, Canada), 10 mM EDTA (Millipore Sigma), 2\% SDS (Roche Diagnostics, Laval, QC, Canada), 500 $\mathrm{mM} \mathrm{NaCl}$ (Thermo Fisher Scientific), $1.5 \mathrm{mM} \mathrm{MgCl}$ (Thermo Fisher Scientific), and $500 \mathrm{mg} / \mathrm{mL}$ of proteinase $\mathrm{K}$ (Qiagen, Montreal, QC, Canada). A standard QIAzol (Qiagen) RNA tissue extraction was performed. The RNA yield was measured using a Nanodrop 2000c spectrophotometer (Thermo Fisher Scientific). RT-qPCR was performed using a SYBR Green I Master hot start reaction mix on a LightCycler 480 Instrument II (Roche Diagnostics). Hprt1, Rpl13a, Tbp, OAZ1, RPS13, and SRP14 were used as DMPK (see Table S2 for primers) normalization controls. RNA integrity was confirmed on MOPS denaturing agarose gels. RNA was isolated from cells using QIAzol for RT-PCR. All RNAs were reverse transcribed using QuantiTect Reverse Transcription kits (Qiagen). Data were analyzed using the Pfaffl method. RT-PCR splicing of 3 replicates per condition was performed with HotStarTaq DNA Polymerase kits (Qiagen) using specific primers (Table S3) and the following conditions: 1 cycle at $94^{\circ} \mathrm{C}$ for $1 \mathrm{~min}, 30$ cycles at $94^{\circ} \mathrm{C}$ for $30 \mathrm{~s}, 58^{\circ} \mathrm{C}$ for $30 \mathrm{~s}$, and one cycle at $72^{\circ} \mathrm{C}$ for $1 \mathrm{~min}$. The PCR products were resolved on Tris-borate-EDTA $1.5 \%$ agarose gels using RedSafe nucleic acid stain (Biotium, Burlington, ON, Canada). Bands were observed using an Alphalmager (Alpha Innotech) and were analyzed by densitometry using the Analyze-Gels function in ImageJ 1.47.

\section{Southern blot analysis}

Genomic DNA was extracted from $2 \times 10^{6}$ cells using FlexiGene DNA kits (Qiagen). The DNA $(20 \mu \mathrm{g})$ was double digested with EcoRV and HindIII (New England Biolabs, Whitby, ON, Canada), isopropanol precipitated, separated by electrophoresis on a 1\% agarose TAE gel, and transferred onto an Immobilon-NY + nylon membrane (Millipore Sigma). The DNA was hybridized overnight at $42^{\circ} \mathrm{C}$ with a human ${ }^{32} \mathrm{P}$-labeled DMPK oligonucleotide probe and was visualized using a Typhoon Trio+ imager (GE Healthcare Life Sciences, Mississauga, ON, Canada).

\section{Cell transfection}

The synthesis and purification of the IONIS 486178 ASO were carried out by Ionis Pharmaceuticals as described previously [64]. See Table S4 for the chemically modified oligonucleotides. DM1 NPCs were transfected using Lipofectamine 3000 reagent (Thermo Fisher Scientific) when they reached $80 \%$ confluence. The ASO was used at final concentrations ranging from 31.25 to $500 \mathrm{nM}$. All analyses were performed after $24 \mathrm{~h}$ on 5 replicates per dose.

\section{Animals}

Experiments involving animals were approved by the local Animal Care and Use Committee of the Research Centre of the Centre Hospitalier Universitaire de Québec (CHUQ). DMSXL transgenic and wild-type (WT) mice were produced in our laboratory. Female and male heterozygous DMSXL mice with 1000-1600 CTG repeats were used at 4 months of age for most experiments, with the exception of 19-day-old mice for the behavioral analyses. The mice were randomized by equally distributing sexes and littermates between groups. Experimental group sizes were determined by a small-scale pilot experiment. No animals were excluded from the analysis, and the investigator was not blinded at any point during the experiments.

\section{Intracerebroventricular injection of the ASO}

Intracerebroventricular (i.c.v.) bolus injections were performed as previously described [65]. The ASO was dissolved and diluted in sterile D-PBS and sterilized by filtration through a $0.22-\mu \mathrm{m}$ filter. The DMSXL mice were anesthetized with isoflurane $\left(4 \%\right.$ in $\left.\mathrm{O}_{2}, 1 \mathrm{~L} / \mathrm{min}\right)$ and were placed in a rat stereotaxic frame (Stoelting, Wood Dale, IL, USA) with ultra-precise manipulator arms (Stoelting). The isoflurane was increased to $2 \%$ in $\mathrm{O}_{2}$ at a flow rate of $0.5 \mathrm{~L} / \mathrm{min}$ (ABBOTT, Mississauga, ON, Canada) through a P28 mouse gas anesthesia head holder. A craniotomy was performed with a 2-mm ball head drill bit to inject $5 \mu \mathrm{L}$ of the ASO with a Neuros syringe (Hamilton, City, QC, Canada) equipped with a 33-G blunt point needle at a rate of $1 \mu \mathrm{L} / \mathrm{s}$ at the following coordinates: $X=1.1 \mathrm{~mm}, Y=-0.2 \mathrm{~mm}$, and $Z=-2.2 \mathrm{~mm}$ from the bregma. After $5 \mathrm{~min}$, the needle was slowly withdrawn, and the skin incision was sutured.

The dose-response experimental group sizes were: Saline $(n=5), 9 \mu \mathrm{g}$ of ASO $(n=5), 19 \mu \mathrm{g}$ of ASO $(n=5), 38 \mu \mathrm{g}$ of ASO $(n=4)$, and $75 \mu \mathrm{g}$ of ASO $(n=5)$. The time-effect experimental group sizes were 5 mice per time point for the IONIS-486178 ASO and 5 mice for the saline per time point.

\section{Immunohistochemistry}

The distribution of ASO in mouse brain tissues was assessed by immunochemistry as described previously [66]. Briefly, fixed brain sections from 3 mice per group were digested for $1 \mathrm{~min}$ at $37^{\circ} \mathrm{C}$ with a solution containing $500 \mathrm{mg} / \mathrm{mL}$ of proteinase $\mathrm{K}$ (Qiagen), $10 \mathrm{mM}$ Tris-Cl, $\mathrm{pH} 7.5$ (Wisent Bioproducts), $10 \mathrm{mM}$ EDTA (Millipore Sigma), 2\% SDS (Roche Diagnostics), $500 \mathrm{mM} \mathrm{NaCl}$ (Thermo Fisher Scientific), and $1.5 \mathrm{mM} \mathrm{MgCl}$ (Thermo Fisher Scientific). They were then blocked with 3\% BSA for 30 min. After two washes in phosphate-buffered saline, the samples were incubated with a polyclonal rabbit anti-ASO primary antibody (6651 Pan ASO; Ionis Pharmaceuticals Inc., Carlsbad, CA, USA) for $1 \mathrm{~h}$ at room temperature and then with a goat anti-rabbit lgG (HRP) secondary antibody. The DAB chromogen (Abcam, Toronto, ON, Canada) was applied for 5 min before nuclear counterstaining with hematoxylin.

\section{Blood chemistry}

Blood from 5 mice per group was collected through the inferior vena cava and was transferred to serum separator tubes (Thermo Fisher Scientific). The blood was incubated at room temperature for $30 \mathrm{~min}$ to allow coagulation and was then centrifuged at $10,000 \times g$ for $5 \mathrm{~min}$. The serum was collected in new tubes and was stored at $-20^{\circ} \mathrm{C}$ for further analysis. Alkaline phosphatase (ALP), alanine transaminase (ALT), aspartate transaminase (AST), creatine kinase (CPK), and creatinine (CRE) levels were measured using Olympus reagents and an Olympus AU400e analyzer (Olympus, Richmond Hill, ON, Canada).

\section{Histological analysis}

Liver and kidney tissues from 5 mice per group were harvested, fixed in $10 \%$ buffered formalin for $24 \mathrm{~h}$, dehydrated in graded ethanol, embedded in paraffin, and stained using hematoxylin and eosin. The histopathological changes were evaluated by an animal pathologist from IDEXX BioAnalytics. The tissues were examined microscopically and changes were graded according to severity, using a standard grading system where $0=$ no significant change, $1=$ minimal, $2=$ mild, $3=$ moderate, and $4=$ severe. Half-points were used to represent intermediate findings.

\section{Neonatal intracerebroventricular injections}

On neonatal day 1 (P1), hypothermic anesthesia was induced by placing the neonatal mice on a cold aluminum plate in ice. Anesthesia was confirmed by a color change from pink to purple, squeezing of paws, and cessation of movement. The mice were then injected with $2 \mu \mathrm{L}$ of the IONIS 486178 ASO $(14 \mu \mathrm{g})$ or $2 \mu \mathrm{L}$ of saline by i.c.v. bolus injections using a Hamilton Neuros syringe with a $33 \mathrm{G}$ needle. The ventricular injection sites were located at the following coordinates: $X=0.8 \mathrm{~mm}, Y=1.5 \mathrm{~mm}$, and $Z=-1.7 \mathrm{~mm}$ from the bregma. The mice were then placed on a warming pad and were allowed to regain movement before being returned to the dam cage.

\section{Open field test}

Mouse activity was tested at 19 and 20 days in square open $40 \times 40 \mathrm{~cm}$ wood boxes. The open field arena was divided into a grid of equal-sized areas for the visual scoring of activity in different zones. Locomotor activity was measured with an infrared photobeam detection system (Any Maze, IL, 
USA). Each mouse was subjected to two 30-min sessions at 24-h intervals. The following data were collected to assess horizontal animal activity: (a) distance traveled, time mobile, and average speed in the apparatus during each 30-min session and (b) the number of entries and duration of visits in the different zones of the open field arena. Group sizes were: WT-Saline ( $n$ $=13)$, DMSXL-Saline $(n=11)$, and DMSXL-IONIS $486178(n=11)$.

\section{Statistical analysis}

All statistical analyses were carried out using PRISM8 software (GraphPad, (A, USA). Data distribution normality was confirmed using the D'AgostinoPearson test for 8 or more values and the Shapiro-Wilk test for fewer than 8 values. When only two groups were compared, the equality of variance was measured using an $F$ test. If the two data sets had identical variances, a standard two-tailed unpaired Student's $t$-test was used. If not, the test was performed with Welch's correction.

When 3 or more groups were compared, the equality of variance was measured using the Brown-Forsythe test. If the data sets had identical variances, an ordinary one-way ANOVA with Tukey's multiple comparisons test was used. If not, a Brown-Forsythe ANOVA test with Games-Howell's multiple comparisons test was performed.

An ordinary two-way ANOVA with Tukey's multiple comparisons test was performed to determine the effect of two independent variables on a dependent variable.

All the statistical tests were performed using a 95\% confidence interval, and the differences were considered significant below the $0.05 \%$ risk threshold $\left({ }^{*} P<0.05,{ }^{* *} P<0.01,{ }^{* *} P<0.001,{ }^{* * *} P<0.0001\right)$.

\section{RESULTS}

\section{DM1 NPC models for antisense oligonucleotide screening}

Human fibroblast cells from a patient with infantile-onset DM1 and a severe intellectual disability and from a control patient were transformed into iPSCs using the Sendai virus technique employing Yamanaka factors (OCT4, KLF4, MYC, and SOX2). The established DM1 (1300 repeats) and control iPSC lines exhibited a typical human stem cell-like morphology under phase contrast microscopy (Fig. S1A). iPSC pluripotency was confirmed by immunostaining for the expression of the OCT4 and NANOG transcription factors, as well as the TRA-1-60, TRA-1-81, and SSEA-4 surface markers (Figs. $1 \mathrm{~A}$ and S1A). The expression of the OCT4, NANOG, DNMT3B, TERT, and REXO1 genes, as determined by RT-PCR, was similar in the human DM1 and control iPSC lines (Fig. S1B). A G-banding analysis showed that there were no karyotypic abnormalities in the human DM1 and control iPSCs (Fig. S1C). To confirm the pluripotency of the huma$n$ iPSCs, we examined their capacity to spontaneously differentiate into the three germ layers. After 16 days in culture, attached cells showed various types of morphology, including those resembling neuronal cells and epithelial cells. RT-PCR confirmed that these differentiated cells expressed lineagespecific markers: TUBB3 and PAX6 (ectodermal lineage), PECAM1, $K D R$, and GATA2 (mesodermal lineage), and GATA4 and AFP (endodermal lineage) (Fig. S1D). These results showed that these iPSCs can differentiate into the three germ layers in vitro with no notable differences between the human DM1 and control iPSC lines.

Forebrain neurons were generated from DM1 and control iPSCs to establish in vitro DM1 models, as previously described by Xia Guangbin [51]. Immunostaining performed at different stages of iPSC differentiation showed that the endogenous pluripotency genes OCT4 and NANOG were downregulated in NPCs (Fig. 1B) while the genes involved in neuronal development (NESTIN and PAX6) were upregulated. In addition, more than $80 \%$ of the cells were positive for TUBB3 after neuronal maturation. Clusters of differentiated neurons expressed FOXG1, suggesting that these neurons had a forebrain identity (Fig. 1C). One of the clear changes observed as the neuronal cultures matured was their ability to repetitively fire APs during an 800-ms depolarizing current step. After 15 days of maturation, the neurons had acquired the ability to generate sodium currents and AP trains and exhibited spontaneous synaptic activities (Fig. 1D, E), confirming their normal biophysical properties.

To determine whether our DM1 in vitro model retained the characteristics of the disease, we assessed its DM1 molecular phenotype. A Southern blot analysis was carried out using genomic DNA isolated from cultured DM1 iPSCs. The blot showed the presence of a large expansion of 1300 CTG repeats in the DMPK gene (Fig. 1F). Furthermore, FISH confirmed the presence of CUG-expanded foci in DM1 iPSCs and NPCs (Figs. 1G and S2). As reported in the literature [67], we also observed a certain variability in the number of nuclear foci, with some DM1 cells containing cytoplasmic CUG foci. This was attributed to different cell cycle stages. During mitosis and with the disruption of the nuclear envelope, most RNA foci disappeared. After cytoplasmic division of the cells, the foci were distributed randomly in their daughter cells. When the nuclear membrane reformed, the foci were either enveloped by the nuclear membrane or remained in the cytoplasm.

We previously identified a 16-nucleotide ASO gapmer (IONIS 486178) that contained cEt modifications targeting exonic regions of DMPK mRNA [59]. Our in vitro strategy consisted of performing a multiple dose evaluation of this ASO to identify the optimal concentration for reducing DMPK mRNA levels. Human DM1 NPCs were transfected with $31.25,62.5,125,250$, or $500 \mathrm{nM}$ of the IONIS 486178 ASO. A quantitative analysis of overall CUG foci performed $24 \mathrm{~h}$ after the treatment revealed a dose-dependent reduction of foci in human DM1 NPCs (Fig. $1 \mathrm{H}$ ), with a maximum $70 \%$ reduction at $500 \mathrm{nM}$. This reduction was associated with the reduction of DMPK mRNAs induced by the IONIS 486178 ASO (Fig. 1I).

\section{Reversal of the DM1 molecular phenotype in DM1 NPCs}

We performed MBNL1 and MBNL2 immunostaining followed by a FISH targeting the CUG repeats in NPCs. We observed a diffuse distribution of MBNL1 and MBNL2 throughout the nuclei of control cells, whereas DM1 cells displayed a dotted pattern that colocalized with RNA foci, supporting the hypothesis that these splicing regulators are sequestered in DM1 NPCs (Fig. 2A, B). One day after a 500-nM IONIS 486178 ASO treatment, we observed that the number of RNA foci in DM1 NPCs was significantly reduced (Fig. 2A, B). A nuclear redistribution of MBNL1 and MBNL2 also occurred, suggesting that CUGexp repeats were successfully destroyed after cleavage events. We subsequently determined whether this reduction was sufficient to rescue the mis-splicing of MBNL1, MBNL2, APP, and GRIN1, which have been reported as DM1 neurological alterations and to be some of the genes with the highest splicing disruptions in human DM1 neuronal cells $[68,69]$. We observed a partial rescue of the MBNL1 and MBNL2 exon 7 exclusion and of the APP exon 7, GRIN1 exon 4, and SORBS1 exon 23 inclusions, which is consistent with the reduction of RNA foci and redistribution of MBNL1 and MBNL2 (Fig. 2C).

Potency of the IONIS 486178 ASO in the DMSXL mouse brain We evaluated the efficacy of the IONIS 486178 ASO for reducing human DMPK mRNAs in the brain following an i.c.v. injection in adult heterozygous DMSXL mice. The ASO was prepared in phosphate-buffered saline and was administered by i.c.v. using a single bolus injection in the right lateral ventricle of the brain. Five mice of mixed genders were treated with $9,19,38$, or $75 \mu \mathrm{g}$ of ASO. Their brains were dissected into 10 regions after 7 days for RNA analysis. An RT-qPCR analysis showed that there was a dosedependent reduction in human DMPK mRNA levels throughout the brain (Fig. $3 \mathrm{~A}$ ). This reduction varied depending on the brain region, with a greater reduction at lower doses for the medulla, pons, hypothalamus, and hippocampus (more than $80 \%$ for $75 \mu \mathrm{g}$ and $70 \%$ for $38 \mu \mathrm{g}$ ). We observed a decrease in human DMPK mRNA expression in the cortex, which did not exceed $70 \%$ with $75 \mu \mathrm{g}$ of the IONIS 486178 ASO. These results demonstrated that the IONIS 486178 ASO is efficiently delivered by i.c.v. to different 
A

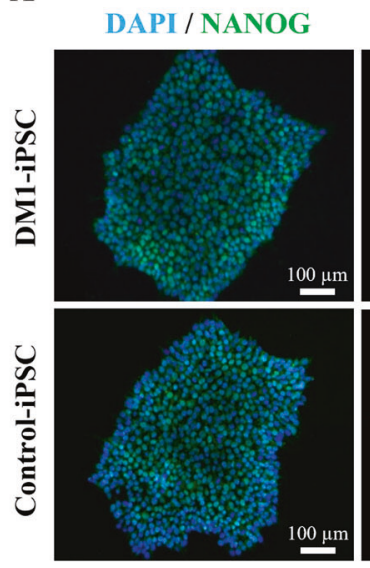

C
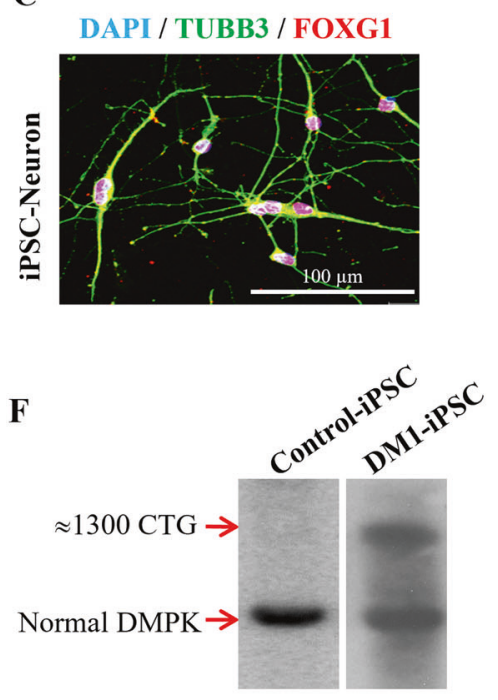

H
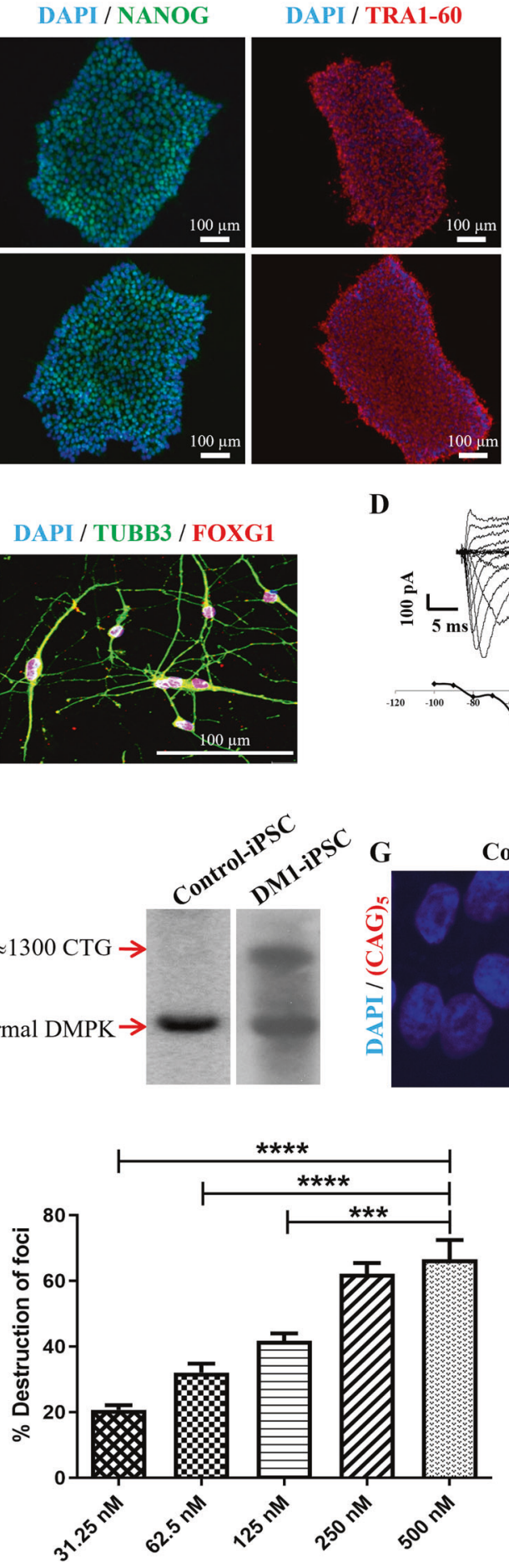

D
B


DM1-iPSC
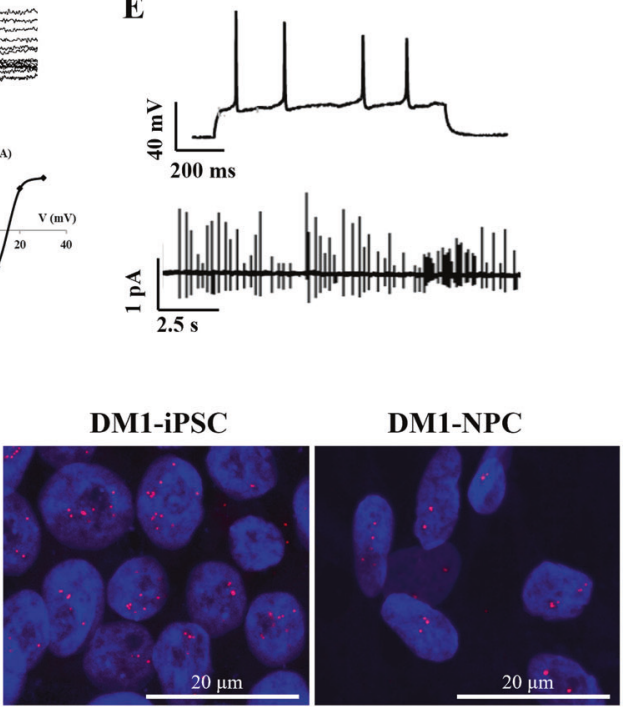

I

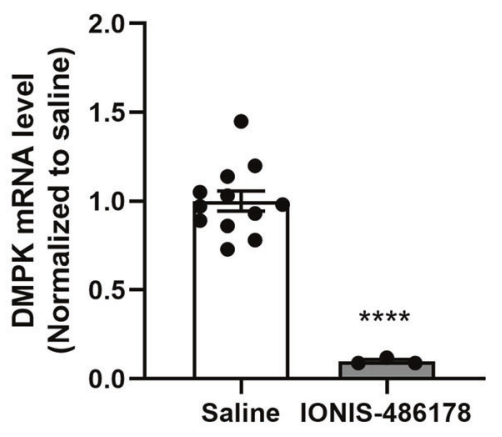

Fig. 1 DM1 NPC model for antisense oligonucleotide screening. A Immunofluorescence of reprogrammed iPSC lines for the surface antigen TRA-1-60 and the nuclear pluripotency marker NANOG. B Loss of the pluripotency markers OCT4 and NANOG and expression of the neuroectodermal markers NES and PAX6. C Forebrain identity of neurons after 15 days of maturation. Patch-clamp measured D sodium currents, and $\mathbf{E}$ action potentials and cell-attached recordings of spontaneous cell firing activity. $\mathbf{F}$ Southern blot of DM1 iPSCs with a large repeat expansion in the DMPK gene. G FISH showing the presence of CUG-expanded foci in DM1 iPSCs and NPCs. H Quantification of overall CUG foci by FISH. Statistical analyses were performed using an ordinary one-way ANOVA with Tukey's multiple comparisons test. I RT-qPCR DMPK mRNA analysis after a treatment with $500 \mathrm{nM}$ IONIS 486178 ASO. A two-tailed unpaired Student's $t$-test with Welch's correction was used to determine the significance between the two groups. The error bars are presented as the mean \pm SEM. SEM standard error of the mean.

brain areas of DMSXL mice is efficient and that it can reduce DMPK mRNA expression in vivo.

To determine the duration of action of the IONIS 486178 ASO in the CNS, we followed its effect on human DMPK mRNA levels over 6 months. Heterozygous DMSXL mice of mixed genders received an i.c.v. bolus injection of $75 \mu \mathrm{g}$ of the IONIS 486178 ASO. Five animals were sacrificed at various times after the injection. An RT-qPCR analysis showed that the maximum effect, 
A
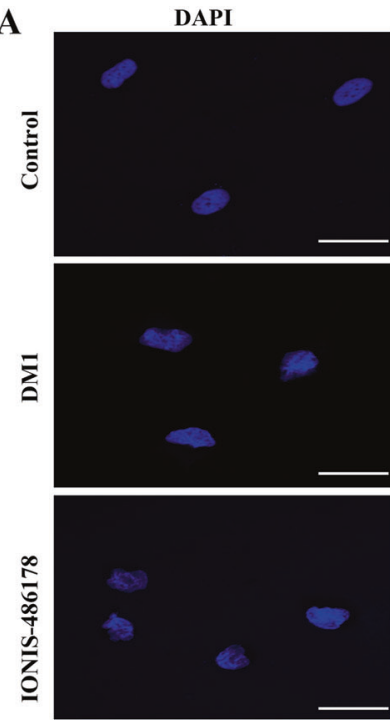

B
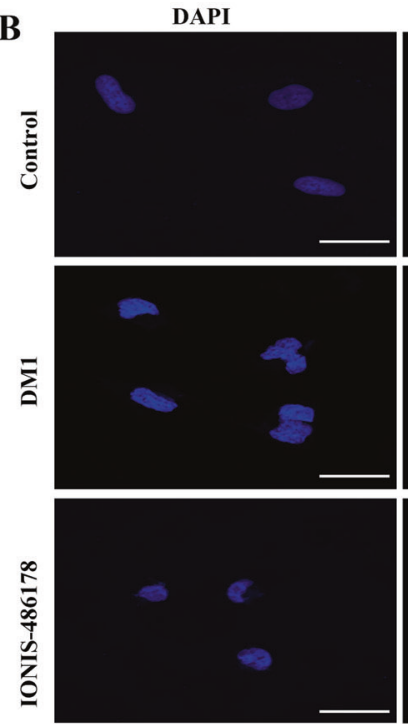

C

MBNL1

MBNL2

PP

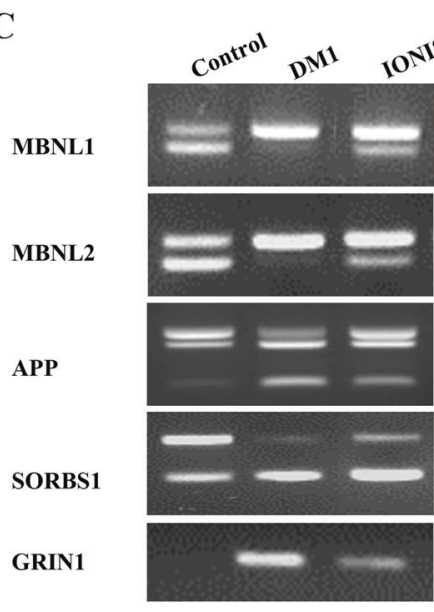

FOCI
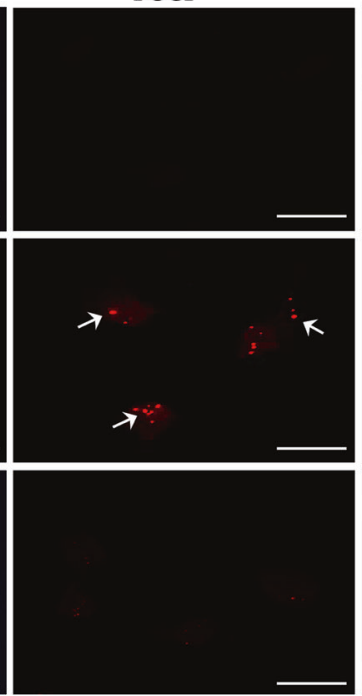

FOCI
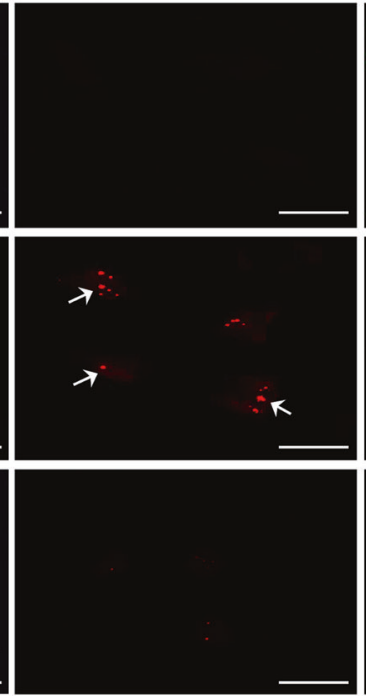

$2012-4860^{18}$
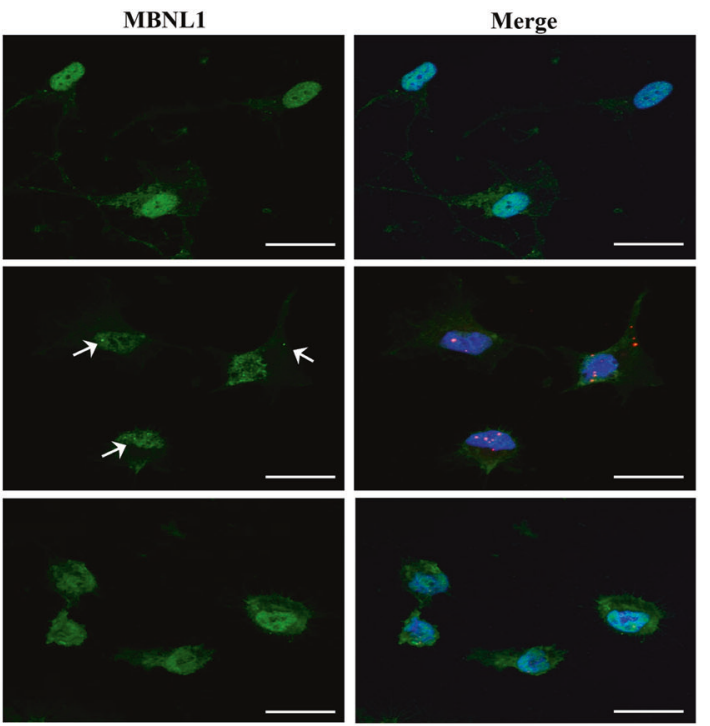

MBNL2
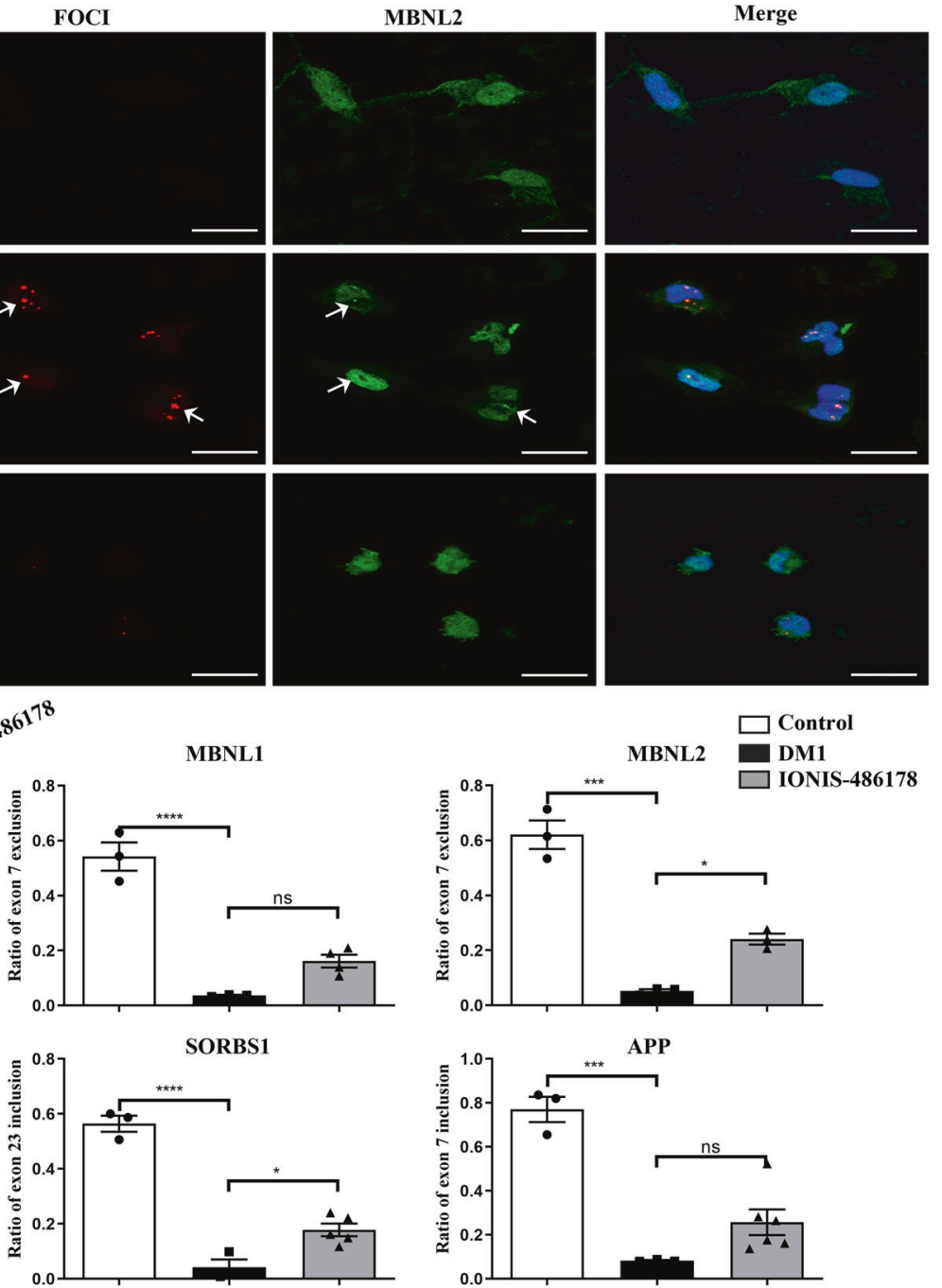

Fig. 2 Correction of NPC DM1 phenotypes after a treatment with the IONIS 486178 ASO. A FISH immunofluorescence showing the destruction of nuclear foci and the redistribution of MBNL1 and B MBNL2 $24 \mathrm{~h}$ after transfection with $500 \mathrm{nM}$ IONIS 486178 ASO. C RT-PCR of DM1 alternative mis-splicing. Statistical analyses were performed using an ordinary one-way ANOVA with Tukey's multiple comparisons test. The error bars are presented as the mean \pm SEM. Scale bar: $20 \mu \mathrm{m}$. 

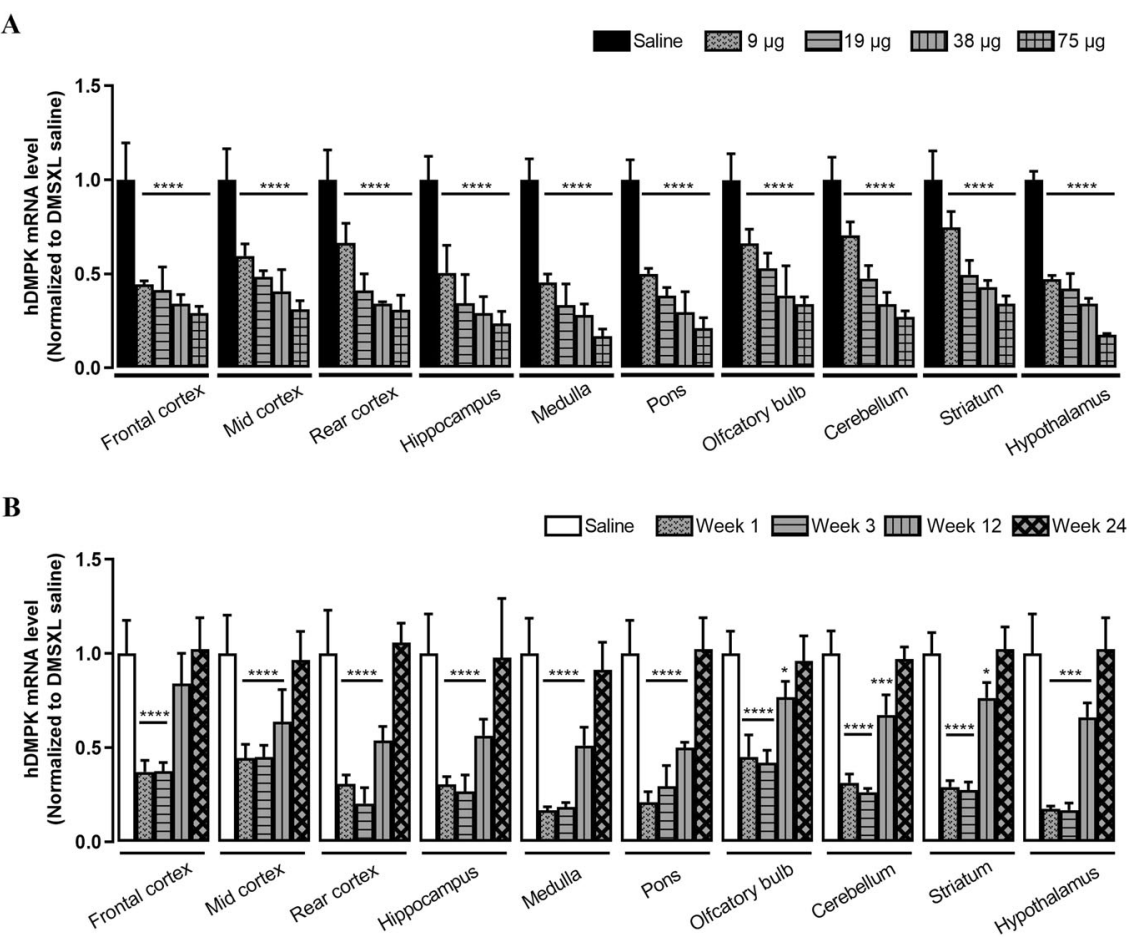

Fig. 3 Intracerebroventricular injection of the IONIS 486178 ASO in DMSXL mice. RT-qPCR hDMPK mRNA analysis of a dose-dependent (A) and a time-dependent (B) ASO treatment in different brain areas. An ordinary two-way ANOVA with Tukey's post hoc analysis for comparing multiple groups was used. The error bars are presented as the mean \pm SD. SD standard deviation.

which ranged from a $55 \%$ to an $83 \%$ reduction in human DMPK mRNAs, depending on the brain region, was maintained for at least 3 weeks after a single injection (Fig. 3B). mRNA knockdown was reduced by $30-50 \% 12$ weeks after the injection and returned to untreated levels after 24 weeks, suggesting that this ASO is stable for 3-12 weeks in CNS tissues.

\section{Brain distribution of the IONIS 486178 ASO}

We assessed the distribution of the IONIS 486178 ASO in the brain starting from the site of injection. Fixed brain sections were stained with a polyclonal antibody (6651 Pan ASO) that specifically recognizes phosphorothioate-modified ASOs [70]. The IONIS 486178 ASO exhibited broad brain distribution, with the greatest accumulations in the hypothalamus, hippocampus, cortex, and cerebellum. IONIS 486178 ASO diffusion to the white and gray matter was consistent (not shown). The IONIS 486178 ASO was detected in a time-dependent manner, with most of the ASO accumulating in the cytoplasm. The IONIS 486178 ASO was partially eliminated after 12 weeks of treatment (Fig. 4).

\section{The IONIS 486178 ASO does not cause CNS inflammation}

To determine the potential toxicity of the IONIS 486178 ASO in adult mice, we first determined whether the delivery by an i.c.v. bolus injection would result in the induction of astroglial (Gfap) and microglial (Aif1) activation, which plays an important role in the immune response [71]. The expression of Aif1 and Gfap in CNS tissues was examined by RT-qPCR. We observed no increase in Aif1 or Gfap mRNA levels in the brain after various treatment times, indicating that there was no significant increase in the number of astroglial and microglial cells (Fig. 5A).

We also investigated whether there was any peripheral toxicity when the IONIS 486178 ASO diffused from the CNS into the systemic circulation. A blood biochemistry analysis showed that the plasma markers ALT, ALP, and AST all remained within normal limits at 1-, 12- and 24-weeks post-injection. Similarly, CRE and CPK levels, which are markers for kidney and tissue damage, respectively, remained within normal thresholds during the experiment (Fig. 5C). Liver and kidney sections examined by an animal pathologist were all normal after 12 and 24 weeks of treatment (Fig. 5B). However, a mild renal pelvic inflammation as well as low numbers of mixed inflammatory cells infiltrating the gall bladder lamina propria were observed. Overall, the IONIS 486178 ASO seemed to be very well tolerated in adult mice following a single $75-\mu \mathrm{g}$ i.c.v. injection.

\section{The IONIS 486178 ASO corrects behavioral abnormalities of DMSXL mice}

Homozygous but not heterozygous DMSXL mice (19-21 days old) have a behavioral phenotype of reduced exploratory activity and increased anxiety, which resembles a myotonic dystrophy type 1 neurological manifestation (Fig. 6D). To evaluate the efficiency of the IONIS 486178 ASO in correcting DM1 brain deficits, we first assessed the effects of a neonatal i.c.v. IONIS 486178 ASO injection in homozygous DMSXL mice. The ASO was prepared in phosphate-buffered saline and was administered as a single i.c.v. bolus injection. Thirteen mice of mixed genders were treated with $14 \mu \mathrm{g}$ of the IONIS 486178 ASO at P1. The brains were harvested after 21 days for mRNA analysis and exhibited a $66 \%$ reduction in human DMPK mRNA levels (Fig. 6A), with no increase in the expression of Aif1 or Gfap (Fig. 6B). Nineteen days after the treatment, the activity of the mice was assessed using the open field test. The number of entries and the duration of visits to the corner zones compared to the central zone of the open field arena indicated that there was a possible increase in anxiety of untreated DMSXL mice (Fig. 6H, I). They exhibited a significant decrease in exploratory activity, time mobility, and average speed shortly after their transfer into the open field arena (Fig. 6E-G), whereas the activity of mice treated with the IONIS 486178 ASO resembled that of WT mice, indicating that this ASO has the potential to correct behavioral abnormalities. To confirm that these results were not due to a correction of motor impairment, we examined the effect of the IONIS 486178 ASO on human DMPK 


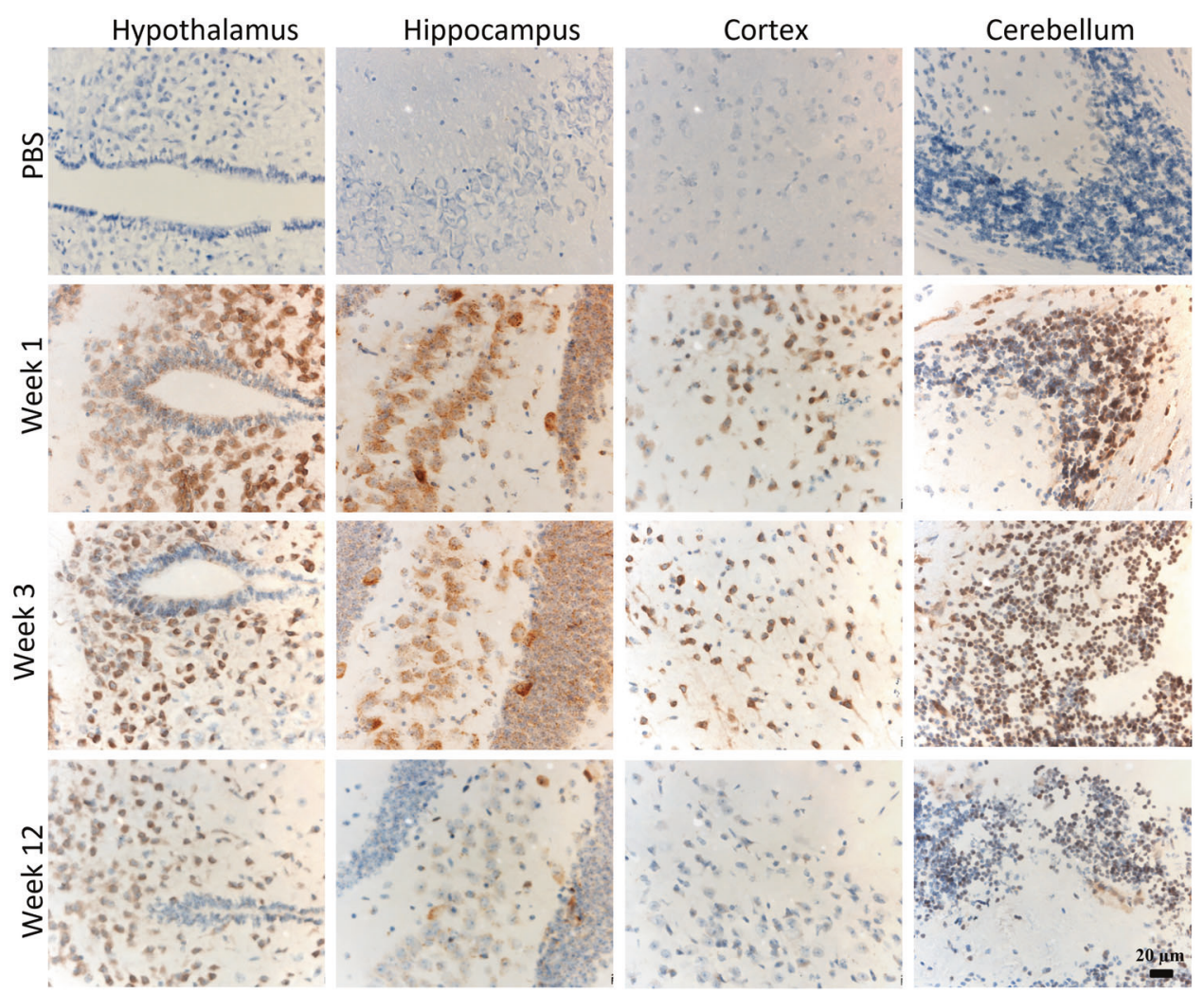

Fig. 4 Mouse brain distribution of the IONIS 486178 ASO. Distribution of the ASO in the DMSXL mouse brain 1, 3, and 12 weeks after a $75 \mu \mathrm{g}$ i.c.v. bolus injection. The ASO was visualized by immunostaining with an anti-ASO antibody (6651 Pan ASO) followed by counterstaining with hematoxylin. The scale bar of all images is shown on bottom right image.

$\mathbf{A}$

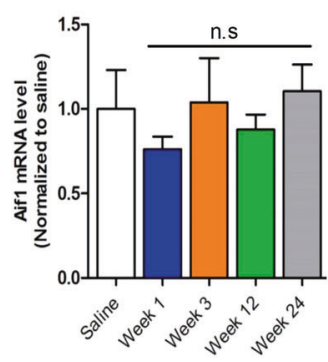

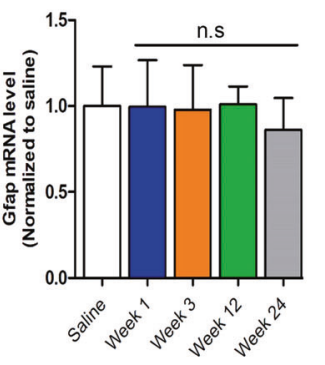

B

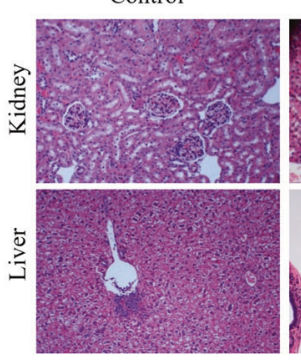

Week 12

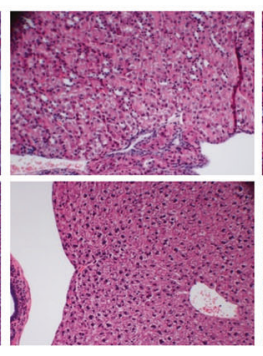

Week 24

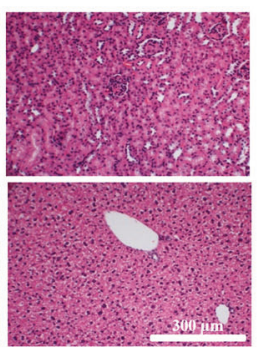

CRE
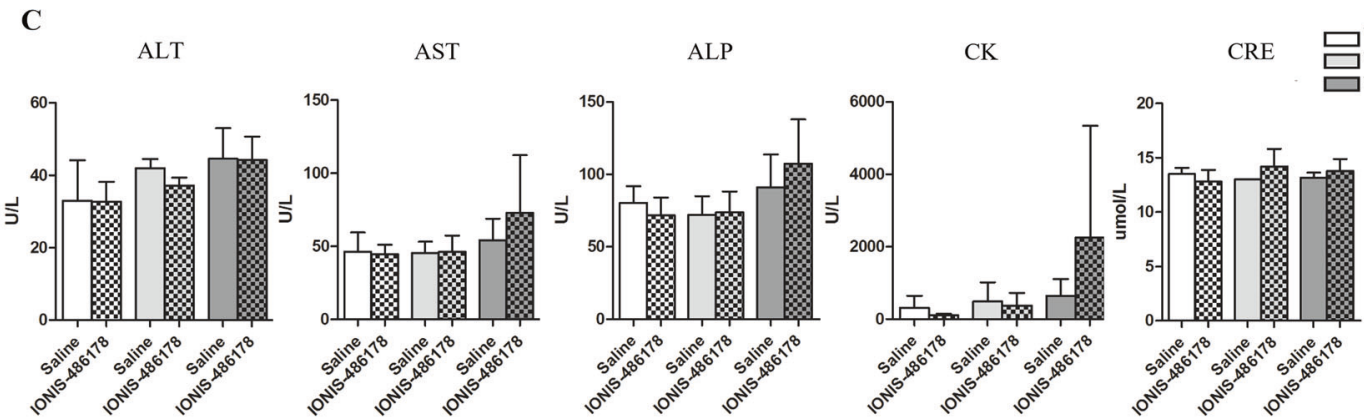

Fig. 5 IONIS 486178 ASO toxicity profile in DMSXL mouse. A Aif1 and Gfap mRNA expression profiles 1, 3, 12, and 24 weeks after a $75 \mu$ i.c.v. bolus injection. Liver and kidney histology (B), the scale bar of all images is shown on bottom right image. Blood chemistry (C). ALP alkaline phosphatase, ALT alanine transaminase, AST aspartate transaminase, CK creatine kinase, CRE creatinine. Statistical analyses were performed using an ordinary one-way ANOVA with Tukey's multiple comparisons test. The error bars are presented as the mean \pm SD. 
A

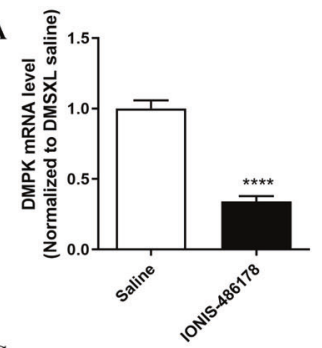

C

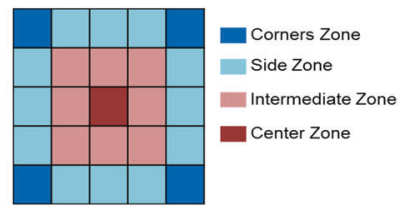

E

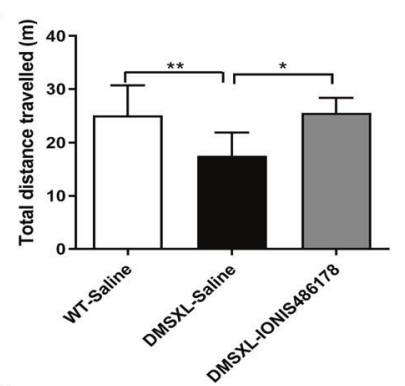

H

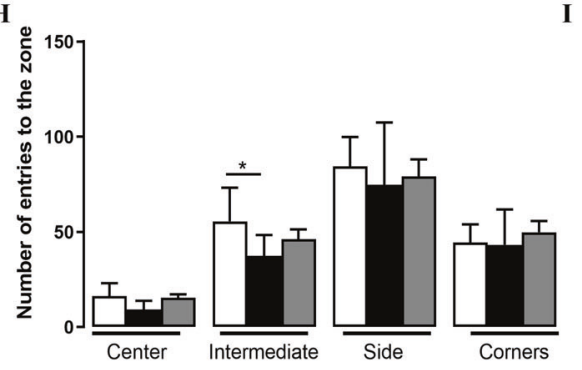

B

D

F
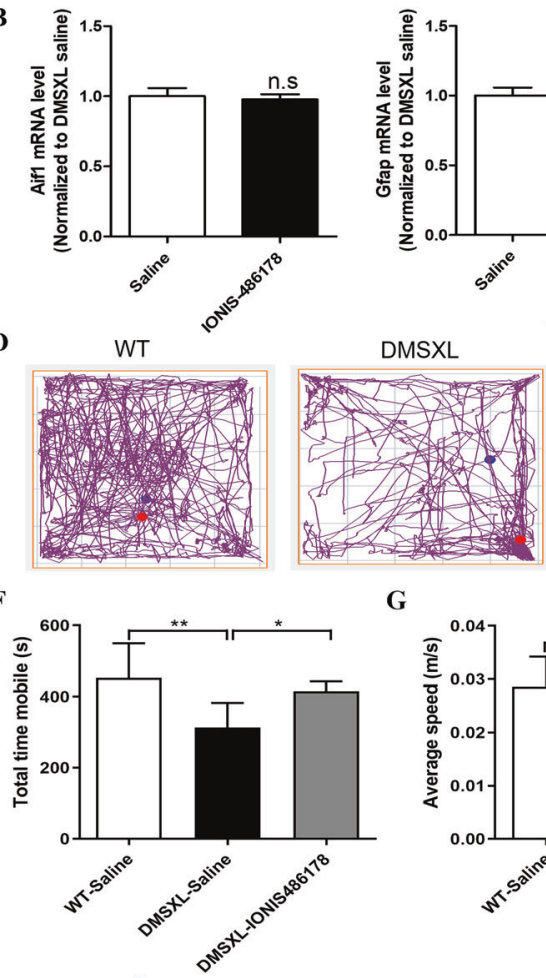

G

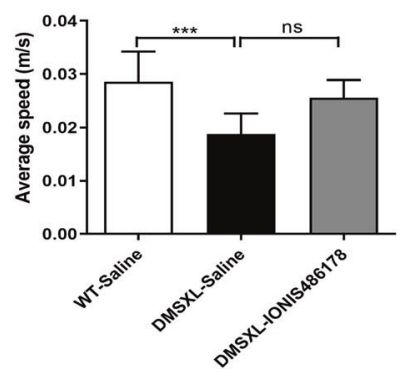

-

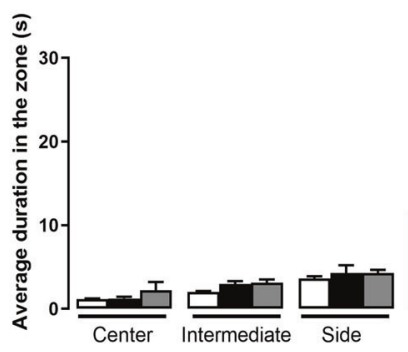

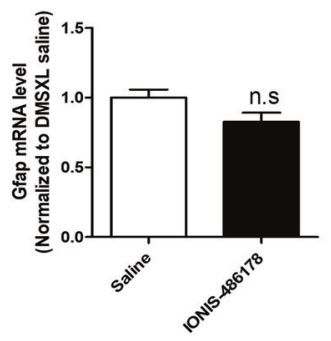

DMSXL+|ONIS-486178

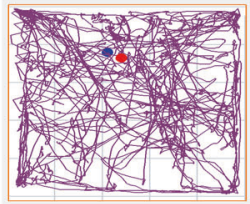

- 14

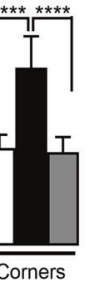

Fig. 6 Behavioral abnormality correction of DMSXL mice after an IONIS 486178 ASO treatment. RT-qPCR hDMPK (A) and Aif1 and Gfap (B) mRNA analysis of the brain. Schematic zones in the open field arena (C) and representative traces of mouse movement (D). Total distance traveled $(\mathbf{E})$, time mobile $(\mathbf{F})$, and average speed $(\mathbf{G})$ of DMSXL homozygote mice. Number of entries into the zone $(\mathbf{H})$ and duration of visit in the zone (I) of the open field arena. The statistical analyses were performed using a standard two-tailed unpaired Student's $t$-test for $\mathbf{A}$ and B, an ordinary one-way ANOVA with Tukey's multiple comparisons test for F. a Brown-Forsythe ANOVA test with Games-Howell's multiple comparisons test for $\mathbf{E}$ and $\mathbf{G}$ and an ordinary two-way ANOVA with Tukey's multiple comparisons test for $\mathbf{H}$ and $\mathbf{I}$. The error bars are presented as the mean \pm SEM for $\mathbf{A}$ and $\mathbf{B}$ or \pm SD for $\mathbf{E}-\mathbf{I}$.

mRNA levels in the tibialis anterior muscle after an i.c.v. injection. The amount of ASO injected had no effect on DMPK mRNA levels in the tibialis anterior muscle (Fig. S3). Moreover, the total dose injected in the CNS was very low compared to the dose necessary to target muscles.

\section{DISCUSSION}

In the present study, we evaluated the efficiency of the IONIS 486178 ASO for correcting the DM1 phenotype in human neural cells derived from iPSCs with 1300 CTG repeats. We showed that the IONIS 486178 ASO reduces nuclear foci, enables nuclear redistribution of $M B N L 1 / 2$, and corrects aberrant splicing. Other studies using gene editing to reverse the mutation have reported similar phenotype reversals in iPSC-derived neurons $[69,72]$. It was shown that early passage NPCs (less than 5 passages) may express both the fetal and adult MBNL isoforms and that the adult-to-fetal splicing ratio increases over time in culture [72]. In the present study, we used passage 4 NPCs. The physiological expression of fetal isoforms may thus explain why a minor but significant reversal of MBNL mis-splicing was observed in DM1 NPCs following a near complete suppression of total DMPK mRNAs by the ASO treatment. These results support the usefulness of iPSC-derived neural cells as a platform for screening potential drugs targeting CNS defects in DM1 brains.

We showed that the IONIS 486178 ASO was effective in targeting DMPK mRNAs, was well tolerated following an i.c.v. bolus injection, and resulted in an impressive downregulation of human DMPK expression throughout the DMSXL mouse brain. We observed the same long-lasting effects in the brain as previously reported for skeletal muscles [60], indicating that this ASO may be used at a similar dose-spacing interval. These data are in agreement with a previous study showing that ASOs exhibit prolonged activity in the CNS [65]. In addition, the brain, blood, liver, and kidney analyses suggested that the IONIS 486178 ASO does not exhibit any local or peripheral toxicity after a single i.c.v. injection. The effect of the IONIS 486178 ASO was previously evaluated in WT mice by subcutaneous injection, which demonstrated that the IONIS 486178 ASO also targets mouse Dmpk transcripts. The reduction in endogenous Dmpk mRNAs in WT mice caused no significant changes in mis-spliced RNAs and had no apparent deleterious effects on skeletal muscle or cardiac function 
$[59,73]$. It is thus likely that the IONIS 486178 ASO also targets mouse Dmpk transcripts in the brain following an i.c.v. injection in DMSXL mice. It is, however, not known whether decreased levels of endogenous Dmpk mRNAs lead to a behavioral phenotype.

CUGexp-RNA nuclear aggregates have been identified in cortical and subcortical neurons in the brain [68]. As in skeletal [74] and cardiac muscles [75], these foci cause a dysregulation of alternative splicing regulators in the brain, inducing the production of aberrant isoforms of developmentally regulated genes in neurons and contributing to cognitive impairment in DM1 patients. In particular, the aberrant splicing of MBNL1, $M B N L 2, A P P, G R I N 1$, and MAPT participate in the synaptic dysfunction and neurofibrillary degeneration seen in DM1 $[15,68]$. Although they are not very easy to detect, the same splicing abnormalities have also been detected in DMSXL mice $[32,33]$. Mbnl2 knockout mice develop significant brain defects, including cognitive deficits, impaired synaptic transmission, and spliceopathy, which testify to the contributing role of MBNL sequestration in DM1 CNS dysfunction [31, 76-79]. In the present study, the biodistribution of the IONIS 486178 ASO in the CNS after an i.c.v. injection was detected in the same areas as the foci [32], which correlates with a reduction in DMPK mRNA levels. This suggests that there is a nuclear redistribution of MBNL1 and MBNL2 and a correction of aberrant splicing, as observed in neuronal cells derived from iPSCs. These findings support the feasibility of a therapy based on the intrathecal administration of an ASO in DM1 patients like that of FDA-approved nusinersen administration for treating SMA.

The potential of the IONIS 486178 ASO for developing therapeutic strategies for congenital DM1 was evaluated after a neonatal i.c.v. injection. We hypothesized that a pre-emptive treatment with the IONIS 486178 ASO would correct behavioral and cognitive impairments. Our results showed that when the IONIS 486178 ASO is delivered to the developing brain, toxic mRNAs are reduced while behavioral abnormalities are significantly improved. As the ASO would be administered by an invasive procedure in human neonates, it would be advantageous to use a molecule with a half-life long enough to allow prolonged activity. Our preclinical data showed that the IONIS 486178 ASO is stable in CNS tissues and meets this criterion. We predict that neonatal IONIS 486178 ASO therapy has the potential to contribute to a therapeutic strategy for the treatment of congenital DM1 disease. A previous study using a type III SMA mouse model reported that earlier therapeutic interventions by embryonic i.c.v. injections are probably more effective than neonatal injections for phenotype correction [80]. However, in both strategies, ASOs led to $90 \%$ SMN2 exon 7 inclusion in P7. Another study delivered an ASO targeting MALAT1 RNAs by transuterine microinjection into mouse amniotic fluid at embryonic day 13 [81]. The ASO reduced target RNA expression for up to 4 weeks after birth and had a persistent effect on postnatal gene expression. To further improve therapeutic outcomes, the effects of the IONIS 486178 ASO will have to be evaluated after a single embryonic injection in utero compared to a neonatal i.c.v. injection.

The IONIS 486178 ASO significantly reduced mutant transcripts in neuronal cells in vitro and generated a robust reduction in $\mathrm{hDMPK}$ mRNA levels in different brain areas of DMSXL mice following an i.c.v. bolus injection. Our data support the development of an ASO therapy for DM1 brain deficits based on intrathecal injection. As this potential DM1 ASO therapy involves relatively invasive delivery methods such as intrathecal multi-dose injections, it is likely that it would have to be coupled with systemic injections to target skeletal muscles.

\section{DATA AVAILABILITY}

The data are available from the corresponding author on reasonable request.

\section{REFERENCES}

1. PS H. Myotonic Dystrophy. London: WB Saunders; 2001.

2. Theadom A, Rodrigues $M$, Roxburgh $R$, Balalla $S$, Higgins $C$, Bhattacharjee $R$, et al. Prevalence of muscular dystrophies: a systematic literature review. Neuroepidemiology. 2014;43:259-68.

3. Bassez G, Lazarus A, Desguerre I, Varin J, Laforet P, Becane HM, et al. Severe cardiac arrhythmias in young patients with myotonic dystrophy type 1. Neurology. 2004;63:1939-41.

4. Groh WJ, Groh MR, Saha C, Kincaid JC, Simmons Z, Ciafaloni E, et al. Electrocardiographic abnormalities and sudden death in myotonic dystrophy type 1 . N Engl J Med. 2008;358:2688-97.

5. Reardon W, Newcombe R, Fenton I, Sibert J, Harper PS. The natural history of congenital myotonic dystrophy: mortality and long term clinical aspects. Arch Dis Child. 1993;68:177-81.

6. Campbell C, Sherlock R, Jacob P, Blayney M. Congenital myotonic dystrophy: assisted ventilation duration and outcome. Pediatrics. 2004;113:811-6.

7. Hageman AT, Gabreëls FJ, Liem KD, Renkawek K, Boon JM. Congenital myotonic dystrophy; a report on thirteen cases and a review of the literature. J Neurol Sci. 1993;115:95-101.

8. Ho G, Cardamone M, Farrar M. Congenital and childhood myotonic dystrophy: Current aspects of disease and future directions. World journal of clinical pediatrics. 2015;4:66-80.

9. Johnson NE, Butterfield R, Berggren $K$, Hung $M$, Chen W, DiBella $D$, et al. Disease burden and functional outcomes in congenital myotonic dystrophy: a crosssectional study. Neurology. 2016;87:160-7.

10. Antonini G, Soscia F, Giubilei F, De Carolis A, Gragnani F, Morino S, et al. Healthrelated quality of life in myotonic dystrophy type 1 and its relationship with cognitive and emotional functioning. J Rehabil Med. 2006;38:181-5.

11. Johnson NE, Luebbe E, Eastwood E, Chin N, Moxley RT, Heatwole CR. The impact of congenital and childhood myotonic dystrophy on quality of life: a qualitative study of associated symptoms. J Child Neurol. 2014;29:983-6.

12. Garcia-Alix A, Cabañas F, Morales C, Pellicer A, Echevarria J, Paisan L, et al. Cerebral abnormalities in congenital myotonic dystrophy. Pediatr Neurol. 1991;7:28-32.

13. Endo A, Motonaga K, Arahata K, Harada K, Yamada T, Takashima S. Developmental expression of myotonic dystrophy protein kinase in brain and its relevance to clinical phenotype. Acta Neuropathol. 2000;100:513-20.

14. Caillet-Boudin ML, Fernandez-Gomez FJ, Tran H, Dhaenens CM, Buee L, Sergeant N. Brain pathology in myotonic dystrophy: when tauopathy meets spliceopathy and RNAopathy. Front Mol Neurosci. 2014;6:57.

15. Sergeant $N$, Sablonnière $B$, Schraen-Maschke $S$, Ghestem $A$, Maurage $C A$, Wattez $A$, et al. Dysregulation of human brain microtubule-associated tau mRNA maturation in myotonic dystrophy type 1. Hum Mol Genet. 2001;10:2143-55.

16. Tanabe $Y$, lai M, Tamai K, Fujimoto N, Sugita K. Neuroradiological findings in children with congenital myotonic dystrophy. Acta Paediatr. 1992;81:613-7.

17. Di Costanzo A, Di Salle F, Santoro L, Bonavita V, Tedeschi G. Brain MRI features of congenital- and adult-form myotonic dystrophy type 1: case-control study. Neuromuscul Disord. 2002;12:476-83.

18. Mutchnick IS, Thatikunta MA, Gump WC, Stewart DL, Moriarty TM. Congenital myotonic dystrophy: ventriculomegaly and shunt considerations for the pediatric neurosurgeon. Childs Nerv Syst. 2016;32:609-16.

19. De Serres-Bérard T, Pierre $M$, Chahine $M$, Puymirat J. Deciphering the mechanisms underlying brain alterations and cognitive impairment in congenital myotonic dystrophy. Neurobiol Dis. 2021;160:105532.

20. Brook JD, McCurrach ME, Harley HG, Buckler AJ, Church D, Aburatani $H$, et al. Molecular basis of myotonic dystrophy: expansion of a trinucleotide (CTG) repeat at the $3^{\prime}$ end of a transcript encoding a protein kinase family member. Cell. 1992;69:385.

21. Fu YH, Pizzuti A, Fenwick RG, King J, Rajnarayan S, Dunne PW, et al. An unstable triplet repeat in a gene related to myotonic muscular dystrophy. Science. 1992;255:1256-8.

22. Mahadevan M, Tsilfidis C, Sabourin L, Shutler G, Amemiya C, Jansen G, et al Myotonic dystrophy mutation: an unstable CTG repeat in the $3^{\prime}$ untranslated region of the gene. Science. 1992;255:1253-5.

23. Harley HG, Brook JD, Rundle SA, Crow S, Reardon W, Buckler AJ, et al. Expansion of an unstable DNA region and phenotypic variation in myotonic dystrophy. Nature. 1992;355:545-6.

24. Taneja KL, McCurrach M, Schalling M, Housman D, Singer RH. Foci of trinucleotide repeat transcripts in nuclei of myotonic dystrophy cells and tissues. J Cell Biol. 1995;128:995-1002.

25. Miller JW, Urbinati CR, Teng-Umnuay P, Stenberg MG, Byrne BJ, Thornton CA et al. Recruitment of human muscleblind proteins to (CUG)(n) expansions associated with myotonic dystrophy. EMBO J. 2000;19:4439-48.

26. Timchenko NA, Cai ZJ, Welm AL, Reddy S, Ashizawa T, Timchenko LT. RNA CUG repeats sequester CUGBP1 and alter protein levels and activity of CUGBP1. J Biol Chem. 2001;276:7820-6. 
27. Kalsotra A, Xiao X, Ward AJ, Castle JC, Johnson JM, Burge CB, et al. A postnatal switch of CELF and MBNL proteins reprograms alternative splicing in the developing heart. Proc Natl Acad Sci USA. 2008;105:20333-8.

28. Mankodi A, Lin X, Blaxall BC, Swanson MS, Thornton CA. Nuclear RNA foci in the heart in myotonic dystrophy. Circ Res. 2005;97:1152-5.

29. Ranum LP, Cooper TA. RNA-mediated neuromuscular disorders. Annu Rev Neurosci. 2006;29:259-77.

30. Batra R, Charizanis K, Manchanda M, Mohan A, Li M, Finn DJ, et al. Loss of MBNL leads to disruption of developmentally regulated alternative polyadenylation in RNA-mediated disease. Mol Cell. 2014;56:311-22.

31. Goodwin M, Mohan A, Batra R, Lee KY, Charizanis K, Fernandez Gomez FJ, et al. MBNL sequestration by toxic RNAs and RNA misprocessing in the myotonic dystrophy brain. Cell Rep. 2015;12:1159-68.

32. Hernández-Hernández $O$, Guiraud-Dogan $C$, Sicot G, Huguet A, Luilier S, Steidl E, et al. Myotonic dystrophy CTG expansion affects synaptic vesicle proteins, neurotransmission and mouse behaviour. Brain. 2013;136:957-70.

33. Hernández-Hernández $O$, Sicot $G$, Dinca DM, Huguet $A$, Nicole $A$, Buée $L$, et al. Synaptic protein dysregulation in myotonic dystrophy type 1: disease neuropathogenesis beyond missplicing. Rare Dis. 2013;1:e25553.

34. Sicot G, Gourdon G, Gomes-Pereira M. Myotonic dystrophy, when simple repeats reveal complex pathogenic entities: new findings and future challenges. Hum Mol Genet. 2011;20:R116-23.

35. Wang ET, Cody NA, Jog S, Biancolella M, Wang TT, Treacy DJ, et al. Transcriptomewide regulation of pre-mRNA splicing and mRNA localization by muscleblind proteins. Cell. 2012;150:710-24.

36. Otero BA, Poukalov $\mathrm{K}$, Hildebrandt RP, Thornton CA, Jinnai K, Fujimura $\mathrm{H}$, et al. Transcriptome alterations in myotonic dystrophy frontal cortex. Cell Rep. 2021; 34:108634.

37. Seznec $H$, Lia-Baldini AS, Duros C, Fouquet C, Lacroix C, Hofmann-Radvanyi $H$, et al. Transgenic mice carrying large human genomic sequences with expanded CTG repeat mimic closely the DM CTG repeat intergenerational and somatic instability. Hum Mol Genet. 2000;9:1185-94.

38. Gomes-Pereira M, Foiry L, Nicole A, Huguet A, Junien C, Munnich A, et al. CTG trinucleotide repeat "big jumps": large expansions, small mice. PLoS Genet. 2007;3:e52.

39. Sicot G, Gomes-Pereira M. RNA toxicity in human disease and animal models: from the uncovering of a new mechanism to the development of promising therapies. Biochim Biophys Acta. 2013;1832:1390-409.

40. Mankodi A, Logigian E, Callahan L, McClain C, White R, Henderson D, et al. Myotonic dystrophy in transgenic mice expressing an expanded CUG repeat. Science. 2000;289:1769-73.

41. Orengo JP, Chambon P, Metzger D, Mosier DR, Snipes GJ, Cooper TA. Expanded CTG repeats within the DMPK $3^{\prime}$ UTR causes severe skeletal muscle wasting in an inducible mouse model for myotonic dystrophy. Proc Natl Acad Sci USA. 2008;105:2646-51.

42. Yin $\mathrm{Q}$, Wang $\mathrm{H}$, Li N, Ding $\mathrm{Y}$, Xie $\mathrm{Z}$, Jin $\mathrm{L}$, et al. Dosage effect of multiple genes accounts for multisystem disorder of myotonic dystrophy type 1 . Cell Res. 2020;30:133-45

43. Nutter CA, Bubenik JL, Oliveira R, Ivankovic F, Sznajder $Ł$, Kidd BM, et al. Cell-typespecific dysregulation of RNA alternative splicing in short tandem repeat mouse knockin models of myotonic dystrophy. Genes Dev. 2019;33:1635-40.

44. Gladman JT, Mandal M, Srinivasan V, Mahadevan MS. Age of onset of RNA toxicity influences phenotypic severity: evidence from an inducible mouse model of myotonic dystrophy (DM1). PLoS One. 2013;8:e72907.

45. García-Alcover I, Colonques-Bellmunt J, Garijo R, Tormo JR, Artero R, Álvarez-Abril $M C$, et al. Development of a Drosophila melanogaster spliceosensor system for in vivo high-throughput screening in myotonic dystrophy type 1. Dis Model Mech. 2014;7:1297-306.

46. de Haro M, Al-Ramahi I, De Gouyon B, Ukani L, Rosa A, Faustino NA, et al. MBNL1 and CUGBP1 modify expanded CUG-induced toxicity in a Drosophila model of myotonic dystrophy type 1. Hum Mol Genet. 2006;15:2138-45.

47. Garcia-Lopez A, Monferrer L, Garcia-Alcover I, Vicente-Crespo M, Alvarez-Abril MC, Artero RD. Genetic and chemical modifiers of a CUG toxicity model in Drosophila. PLoS One. 2008;3:e1595.

48. Todd PK, Ackall FY, Hur J, Sharma K, Paulson HL, Dowling JJ. Transcriptional changes and developmental abnormalities in a zebrafish model of myotonic dystrophy type 1. Dis Model Mech. 2014;7:143-55.

49. Machuca-Tzili LE, Buxton S, Thorpe A, Timson CM, Wigmore $\mathrm{P}$, Luther PK, et al. Zebrafish deficient for Muscleblind-like 2 exhibit features of myotonic dystrophy. Dis Model Mech. 2011;4:381-92.

50. Martineau L, Racine V, Benichou SA, Puymirat J. Lymphoblastoids cell lines Derived iPSC line from a 26-year-old myotonic dystrophy type 1 patient carrying (CTG). Stem Cell Res. 2018;26:103-6.

51. Xia G, Santostefano KE, Goodwin M, Liu J, Subramony SH, Swanson MS, et al. Generation of neural cells from DM1 induced pluripotent stem cells as cellular model for the study of central nervous system neuropathogenesis. Cellular Reprogram. 2013;15:166-77.

52. Poulin H, Martineau L, Racine V, Puymirat J, Chahine M. Differentiation of lymphoblastoid-derived iPSCs into functional cardiomyocytes, neurons and myoblasts. Biochem Biophys Res Commun. 2019;516:222-8.

53. Poulin $H$, Mercier A, Djemai $M$, Pouliot V, Deschenes I, Boutjdir M, et al. iPSCderived cardiomyocytes from patients with myotonic dystrophy type 1 have abnormal ion channel functions and slower conduction velocities. Sci Rep. 2021;11:2500.

54. Algalarrondo V, Wahbi K, Sebag F, Gourdon G, Beldjord C, Azibi K, et al. Abnormal sodium current properties contribute to cardiac electrical and contractile dysfunction in a mouse model of myotonic dystrophy type 1. Neuromuscul Disord. 2015;25:308-20.

55. Huguet A, Medja F, Nicole A, Vignaud A, Guiraud-Dogan C, Ferry A, et al. Molecular, physiological, and motor performance defects in DMSXL mice carrying $>1,000$ CTG repeats from the human DM1 locus. PLoS Genetics. 2012;8:e1003043.

56. Panaite PA, Kuntzer T, Gourdon G, Lobrinus JA, Barakat-Walter I. Functional and histopathological identification of the respiratory failure in a DMSXL transgenic mouse model of myotonic dystrophy. Dis Model Mech. 2013;6:622-31.

57. Klein AF, Dastidar S, Furling D, Chuah MK. Therapeutic Approaches for Dominant Muscle Diseases: Highlight on Myotonic Dystrophy. Curr Gene Ther. 2015;15:329-37.

58. Wheeler TM, Leger AJ, Pandey SK, MacLeod AR, Nakamori M, Cheng SH, et al. Targeting nuclear RNA for in vivo correction of myotonic dystrophy. Nature. 2012;488:111-5.

59. Jauvin D, Chretien J, Pandey SK, Martineau L, Revillod L, Bassez G, et al. Targeting DMPK with Antisense Oligonucleotide Improves Muscle Strength in Myotonic Dystrophy Type 1 Mice. Mol Therap Nucleic Acids. 2017;7:465-74.

60. Pandey SK, Wheeler TM, Justice SL, Kim A, Younis HS, Gattis D, et al. Identification and characterization of modified antisense oligonucleotides targeting DMPK in mice and nonhuman primates for the treatment of myotonic dystrophy type 1. J Pharmacol Exp Therap. 2015;355:329-40.

61. Yadava RS, Yu Q, Mandal M, Rigo F, Bennett CF, Mahadevan MS. Systemic therapy in an RNA toxicity mouse model with an antisense oligonucleotide therapy targeting a non-CUG sequence within the DMPK $3^{\prime} U T R$ RNA. Hum Mol Genet. 2020;29:1440-53.

62. Dolgin E. Spinal muscular atrophy approval boosts antisense drugs. Nat Biotechnol. 2017;35:99-100.

63. Chatelier A, Dahllund L, Eriksson A, Krupp J, Chahine M. Biophysical properties of human Na v1.7 splice variants and their regulation by protein kinase A. JNeurophysiol. 2008;99:2241-50.

64. Cheruvallath ZS, Kumar RK, Rentel C, Cole DL, Ravikumar VT. Solid phase synthesis of phosphorothioate oligonucleotides utilizing diethyldithiocarbonate disulfide (DDD) as an efficient sulfur transfer reagent. Nucleosides Nucleotides Nucleic Acids. 2003;22:461-8.

65. Rigo F, Chun SJ, Norris DA, Hung G, Lee S, Matson J, et al. Pharmacology of a central nervous system delivered 2'-O-methoxyethyl-modified survival of motor neuron splicing oligonucleotide in mice and nonhuman primates. J Pharmacol Exp Therap. 2014;350:46-55.

66. Hung G, Xiao X, Peralta R, Bhattacharjee G, Murray S, Norris D, et al. Characterization of target mRNA reduction through in situ RNA hybridization in multiple organ systems following systemic antisense treatment in animals. Nucleic Acid Ther. 2013;23:369-78.

67. Xia G, Ashizawa T. Dynamic changes of nuclear RNA foci in proliferating DM1 cells. Histochem Cell Biol. 2015;143:557-64.

68. Jiang $\mathrm{H}$, Mankodi A, Swanson MS, Moxley RT, Thornton CA. Myotonic dystrophy type 1 is associated with nuclear foci of mutant RNA, sequestration of muscleblind proteins and deregulated alternative splicing in neurons. Hum Mol Genet. 2004;13:3079-88.

69. Xia G, Gao Y, Jin S, Subramony SH, Terada N, Ranum LP, et al. Genome modification leads to phenotype reversal in human myotonic dystrophy type 1 induced pluripotent stem cell-derived neural stem cells. Stem Cells. 2015;33:1829-38.

70. Butler M, Stecker K, Bennett CF. Cellular distribution of phosphorothioate oligodeoxynucleotides in normal rodent tissues. Lab Investig. 1997;77:379-88.

71. Yang ZF, Ho DW, Lau CK, Lam CT, Lum CT, Poon RT, et al. Allograft inflammatory factor-1 (AIF-1) is crucial for the survival and pro-inflammatory activity of macrophages. Int Immunol. 2005;17:1391-7.

72. Gao Y, Guo X, Santostefano K, Wang Y, Reid T, Zeng D, et al. Genome Therapy of Myotonic Dystrophy Type 1 iPS Cells for Development of Autologous Stem Cell Therapy. Mol Therap. 2016;24:1378-87.

73. Carrell ST, Carrell EM, Auerbach D, Pandey SK, Bennett CF, Dirksen RT, et al. Dmpk gene deletion or antisense knockdown does not compromise cardiac or skeletal muscle function in mice. Hum Mol Genet. 2016;25:4328-38.

74. Lin X, Miller JW, Mankodi A, Kanadia RN, Yuan Y, Moxley RT, et al. Failure of MBNL1-dependent post-natal splicing transitions in myotonic dystrophy. Hum Mol Genet. 2006;15:2087-97. 
75. Wang GS, Kearney DL, De Biasi M, Taffet G, Cooper TA. Elevation of RNA-binding protein CUGBP1 is an early event in an inducible heart-specific mouse model of myotonic dystrophy. J Clin Investig. 2007;117:2802-11.

76. Kanadia RN, Johnstone KA, Mankodi A, Lungu C, Thornton CA, Esson D, et al A muscleblind knockout model for myotonic dystrophy. Science. 2003;302:1978-80.

77. Charizanis K, Lee KY, Batra R, Goodwin M, Zhang C, Yuan Y, et al. Muscleblind-like 2-mediated alternative splicing in the developing brain and dysregulation in myotonic dystrophy. Neuron. 2012;75:437-50.

78. Lee KY, Li M, Manchanda M, Batra R, Charizanis K, Mohan A, et al. Compound loss of muscleblind-like function in myotonic dystrophy. EMBO Mol Med. 2013;5:1887-900.

79. Lee KY, Chang HC, Seah C, Lee L. Deprivation of Muscleblind-Like Proteins Causes Deficits in Cortical Neuron Distribution and Morphological Changes in Dendritic Spines and Postsynaptic Densities. Front Neuroanat. 2019;13:75.

80. Hua Y, Sahashi K, Hung G, Rigo F, Passini MA, Bennett CF, et al. Antisense correction of SMN2 splicing in the CNS rescues necrosis in a type III SMA mouse model. Genes Dev. 2010;24:1634-44.

81. Depreux FF, Wang L, Jiang H, Jodelka FM, Rosencrans RF, Rigo F, et al. Antisense oligonucleotides delivered to the amniotic cavity in utero modulate gene expression in the postnatal mouse. Nucleic Acids Res. 2016;44:9519-29.

\section{ACKNOWLEDGEMENTS}

This work was supported by lonis Pharmaceuticals Inc., the French Muscular Dystrophy Association (grant \#21438 to JP), and the American Muscular Dystrophy Association (grant \#417929 to JP). This work was also supported by the Canadian Institutes of Health Research (grants MOP-111072 and MOP-130373 to MC) and by U.S. Department of Defense grant (USAMRAA W81XWH-21-1-0426) to MC. We thank Hugo Poulin for his help with the electrophysiological experiments. The human and mouse art pieces used in the graphical abstract were provided by Servier Medical Art (https://smart.servier.com). Servier Medical Art is licensed under a Creative Commons Attribution 3.0 Unported License.

\section{AUTHOR CONTRIBUTIONS}

$S A B$ and JP conceived the paper. $S A B$ wrote the manuscript, performed experiments, and analyzed the data. DJ, TDSB, MP, and MC contributed to the experiments. FR, CFB, and KKL are employees of lonis Pharmaceuticals and contributed to the development of the antisense drugs. GG generated the DMSXL mice. All the authors revised and approved the manuscript.
ETHICAL APPROVAL

All animal experiments were approved by the Institutional Animal Care and Use Committee at CRCHU de Québec.

\section{COMPETING INTERESTS}

$\mathrm{KKL}$, CFB, and FR are employees of lonis Pharmaceuticals. The remaining authors declare no competing interests.

\section{ADDITIONAL INFORMATION}

Supplementary information The online version contains supplementary material available at https://doi.org/10.1038/s41434-022-00316-7.

Correspondence and requests for materials should be addressed to Mohamed Chahine.

Reprints and permission information is available at http://www.nature.com/ reprints

Publisher's note Springer Nature remains neutral with regard to jurisdictional claims in published maps and institutional affiliations.

\begin{abstract}
(c) (i) Open Access This article is licensed under a Creative Common Attribution 4.0 International License, which permits use, sharing adaptation, distribution and reproduction in any medium or format, as long as you give appropriate credit to the original author(s) and the source, provide a link to the Creative Commons license, and indicate if changes were made. The images or other third party material in this article are included in the article's Creative Commons license, unless indicated otherwise in a credit line to the material. If material is not included in the article's Creative Commons license and your intended use is not permitted by statutory regulation or exceeds the permitted use, you will need to obtain permission directly from the copyright holder. To view a copy of this license, visit http://creativecommons. org/licenses/by/4.0/.
\end{abstract}

(c) The Author(s) 2022 